\title{
Conflict Management in Ethnic Tension Zones: Sport Contribution in Co-existence and Inclusion Citizenship Diversity: A Case Study in Aleksandria, Iraq
}

\author{
Sanaa Ali Ahmed Alrashid \\ Physical Education and Sport Sciences College, University of Basrah, Basrah, Iraq
}

Email address:

alrashidsanaa@gmail.com

\section{To cite this article:}

Sanaa Ali Ahmed Alrashid. Conflict Management in Ethnic Tension Zones: Sport Contribution in Co-existence and Inclusion Citizenship Diversity: A Case Study in Aleksandria, Iraq. American Journal of Sports Science. Vol. 8, No. 4, 2020, pp. 99-104.

doi: 10.11648/j.ajss.20200804.14

Received: October 23, 2020; Accepted: November 3, 2020; Published: December 4, 2020

\begin{abstract}
The aim of the study was to strived to know how sports can be used as a tool in Co-existence and inclusion citizenship diversity, conflict resolution management and positive communication. This article seeks to move beyond a simplistic approach that asserts the sports are powerful to a richer articulation of how they function in conflict management. In order to achieve this desired outcome, qualitative design was employed. The sample consited of individuals associated with governmental and intergovernmental sport organizations, sports federations, as well as local athletes and community activists. Data was anlyzed using qualitative interpertive research. Analysis shows that sport work as tackle ethnic tension by animate positive ocmmunication plan settelment and resoluations conflict, trama healing and implement vital interventions conflict transformation and blocked violence. Results of this study contribute to developing the role of sports conflict management tool contribute to build peaceful and sustainable societies, and faces current challenges in ethnic tension zones, productively used to promote co-existence and inclusive citizenship diversity. Changes in approaches of conflict management entail close cooperation between policymakers, international organsiations and civil-society initiatives. Relating sports to peace-building agendas necessitates bridging the gap between reality on the ground and policy-making and demonstrate sport culture as part of a range of solutions in confilict management.
\end{abstract}

Keywords: Conflict Management, Ethnic Tension, Co-existence, Citizenship Diversity

\section{Introduction}

ISIL ethnic cleansing is 'caused irreparable damage to the fabric of Iraq's society, and fuelling inter-ethnic, sectarian and inter-religious tensions in the region and beyond' [1]. There are concerns about the lack of a peacebuilding strategy to compliment the military operations against ISIL. PAX [2] warns, that without a peacebuilding strategy, there is a 'serious risk of gross human rights violations, revenge operations and further ethnic cleansing laying the ground for further conflict'. Military defeat of ISIL will not bring security and stability to Iraq if the underlying tensions between Sunnis and Shias, and Arabs and Kurds, are not addressed [3]. There is a gap in the literature when it comes to examining confilict management platforms in Iraq. Peace operations in Iraq reflect the marginalization of the social and psychological contributors to the conflict. Signing peace agreements and efforts to implement them within conflict areas and building positive relations between sects. The limited interest in addressing the social and psychological contributors to the conflict highlights the need to investigate tools that can be used to address ethnic tension and disrupt a culture of violence in Iraqi society. [4]. Around the world, sport has been used in projects designed to address the social and psychological aspects of conflict. These include projects aimed at contributing to peacebuilding through trauma treatment, peace education, and (re) building relationships. and build a bridges of understanding. This requires long-term efforts in Iraqi societies to use sports in coexistence and positive communication towards reconciliation between opponents and building visions for a cooperative future and 
sustainable peace. $[5,6]$. The purpose of this research is to determine the extent of the contribution of sports in Peaceful coexistence and citizenship inclusive diversity, and determine how sports can be productively used to promote Peaceful coexistence and citizenship inclusive diversity. The high-level political endorsement of a role for sport in development and peace complements various independent grassroots development and aid projects. These include sport-based programmes, education (about racism, drugs, the rights of the child, immunisation, HIV / AIDS, etc), promoting citizenship, combating anti-social behaviour, tackling homelessness and truancy, peacebuilding. Sport creates a feeling of self-worth a sense of belonging a sense of responsibility, a spirit of enjoyment connections between communities freedom new networks, opens doors positive coping mechanisms, shared identities amongst opposing groups, space for dialogue team spirit valuable partnerships [7]. Furthermore, Sport improves cognitive vitality quality of life self-confidence. Selfesteem, superordinate, peace objectives [8]. Sport develops empathy between community members trust between opposing parties conflict transformation of youth life skills longer, healthier quality of life, positive connections with peers and adults, positive social values and life skills relationships among different communities role models. Increasingly across the globe, sports has been utilized in projects designed to address social-psychological aspects of conflict. These include projects aiming to contribute to peacebuilding through healing trauma, educating for peace, developing self-expressive capacities, and (re)building relationships. peace practitioners can utilize sport to stimulate psychological shifts conducive to peace [9]. Sport provides a space to play a unique platform for communication, a unique platform for outreach opportunities, an outlet to control aggression, empowerment for people for advocacy, empowerment to individuals, empowerment to communities, incentive for youth to leave gangs, the ability to create new, shared identities. Sport helps commitment to collective responsibility dismantle gangs facilitate reintegration into society, heal community from psychosocial trauma, stimulate social interactions the healing process, rebuild social relationships develop citizenship values [10]. In the case of Iraq, the importance of this research lies in being the cornerstone in highlighting significant of sport in Iraqi society in contribute to rapprochement, dialogue and reconciliation among peoples, promote Peaceful coexistence fully optimize the federating capacity of sport, pand citizenship inclusive diversity to reframing social relations between communities and groups that have been disrupted due to conflict.

\section{Methedology}

Qualitative, Interpretive Research: The data collected for this study draws heavily on qualitative research. Semistructured interviews were primarily used to collect viable information from various sources. These sources included various individuals associated with governmental and intergovernmental sport organizations, SDP academia, stakeholders, donors and sports federations, as well as local athletes and community activists. each interviewee did request to remain anonymous to an extent that freed them to speak more openly - relative to the conditions - and offered slightly more credibility to their contributions as well as to the overall research design. To obtain a large spectrum of information, the decision was made to conduct semistructured interviews from different types of stakeholders. The information gathered was then assessed, transcribed, identified into categories, and arranged into patterns through the use of coding. For the data collection methods whice were utilized, researcher conducted one-to-one interviews in the following formats: five faceto-face interviews; ten interviews via video conference. Prior to starting each interview, the respective participants and the researcher would share brief, casual conversation, engendering a friendly atmosphere. I reminded the participants that I was merely looking for any information they wished to share and that I would do my best to ensure a sense of safety within the conversation throughout the interview. Also, to ensure that participants were comfortable with the research topic and questions prior to agreeing to partake in the research study, the researcher sent participants the questions that were planned to ask during the interview process, offering as much transparency. Furthermore, the researcher reviewed the Informed Consent Letter with participants, which outlined the participatory nature of the agreement, the purpose, relevant definitions, the interview questions, potential risks and benefits to participants, confidentiality, and contact information for the researcher. all the interviews had been recorded audio each interview, and, after the completion of each interview, transcribed the results. "Qualitative Data Analysis" had been employed "Interpretation" as framework when trying to make meaning of the data collected [11]. such an approach would help to deeply explore the anecdotal evidence that the participants shared. In order to illuminate all-toooften invisible perspectives, the researcher tried understanding of valuable stories and information that participants shared. The first step of this process was a "Data Preparation Phase," which included transcribing the data and deciding what results to focus on [11]. During the transcription process, notes had been taken and wrote memos for important points shared by participants and common threads that evolved, analyzing and interacting with the data throughout the entire process. transcribe has been chosen as it would be a thorough and comprehensive way of reexperiencing, reimagining, and reviewing the data with a fresh perspective. My next two steps of the data analysis process were incorporating a "Data Exploration Phase" and a "Data Reduction Phase" [11]. In the "Data Exploration Phase," researcher began to think about the data gathered and noted and categorized highlights that I deemed relevant to the research process. From these findings and notes, researcher began to summarize and code these findings, employed the use of the "Grounded Theory Approach" [11] in which first 
collected the data, and organized it based on salient themes emerging from the results of the coding and notation processes. Essentially, the process entailed the attempt to most comprehensively understand and analyze the data through "immersion," organizing the data into groups, "chunking," and bringing meaning to such information, through "interpretation" [12].

\section{Results and Discussion}

This section outlines the Literature areas in which responses from interviewees overlapped with theories or understandings represented in the literature. The majority of these findings were based on the strength of the sport to promote personal transformation, conflict settelment: reconciliation and open Dialogue. Also, stimulate coflict resolution: reintegration and awaken consciousness of Violence Prevention cultcure. In addition, the rehabilitation and Therapeutic Healing: Enhanced Sense of Identity and Affiliation, and finaly animating conflict transformation and spiriting reconstruction.

\subsection{Overlap 1}

Opening means of Dialogue conflict settelment: reconciliation and open Dialogue. The stages of challenging assumptions, changing attitudes, and arriving at mutual understanding are all present in the process of dialogue as a tool in conflict resolution [13]. Dialogue in this sense is "a conversation or exchange of ideas that seeks mutual understanding through the sharing of perspectives. It is a process which is generally facilitated by a third party in which different groups can learn about each other's beliefs, feelings, interests, and needs spontaneously [14]. Lederach [15] asserts that dialogue is essential to the conflict transformation process.

All interviewees spoke about dialogue as an effect of their work they used sports and exercises strategically to foster dialogue. Nonetheless, these four interviewees explicitly noted that their work led to dialogue in some capacity, either between participants or between participants and audience members. They saw their teams work as sort of a means of "setting the container" or creating a safe space for a dialogue to take place. It's taught participants how to facilitate dialogue between audience members and participants. it is recognized that "when ethnic tensions are still too intense, sport must first begin to be integrated on both sides in order to create the right conditions for a subsequent sporting meeting" [16]. There is a sober realization of what sport is capable of within the realm of development. In essence, they do not view sport as the omnipotent cure, but instead as one key ingredient amongst many others.

\subsection{Overlap 2}

A Means toward coflict resolution: reintegration and consciousness of violence prevention cultcure.

An additional effect that interviewees touched on, was how their initiatives resulted in participants' increased emotional awareness, which fostered a decrease in violent behavior. It is seems that participating in sports activities creat an emotional awareness, and the end result of a decrease in violent behavior in participants. One example of this is the interviewee who mentioned attributed his decrease in violent behavior to his participation in the initiative. other interviewees simply mentioned the possibility that participation in the initiative could have led to a prevention of violent behavior in participants. The relations between sport and violence, revolves around the idea that this activity may be instrumental in preventing deviant and antisocial behavior as well as it can potentially assist in the rehabilitation of offenders. These steps aim at building relationships and confidence, establishing lines of communication and exploring solutions that could meet both sides' interests and needs. The specific steps to achieve an atmosphere of trust and dialogue will differ from context to context. Hence, it is crucial to understand not only the culture(s) of the parties involved, but the history of the conflict and the issues at stake, i.e., thorough conflict analysis prior to programme implementation including joint meetings with conflict parties. Koshland [17] cite in his article in regards, increased emotional awareness and violence prevention, there who designed and evaluated a violence prevention program for elementary-school students with a focus on movement and kinetic expression to teach participants emotional awareness. Kornblum [18] also who has used movements and kinetic expression to raise emotional awareness as a means to reduce and prevent violence. Sport can reinforce interaction between communities, peoples and societies and hence plays a part in maintaining open channels of communication in open or dormant situations of conflict. In conflict and post-conflict situations, sport can support building a beneficial outlet for people affected which is directed towards peaceful reduction of hostilities and tensions. In addition, sport can contribute to managing trauma after natural disasters or violence in refugee camps [19].

\subsection{Overlap 3}

Ameans toward the rehabilitation and Therapeutic Healing: Enhanced Sense of Identity and Affiliation. The therapeutic effects of sport were touched on in the literature in the fields of psychology, peacebuilding, and sportology. In fact, the majority of the literature reviewed for this research focused on how sports, including all categories, could lead to healing in individuals and help them to deal with past traumas. Psychotherapists, peacebuilders, and sport scholars alike all referenced the connection between sport and emotion [20]. Additionally, scholars from each field claimed that this emotional connection made all sport forms effective means for emotional expression [21]. Certain literature in peacebuilding and psychology then linked this to therapeutic healing. This idea of forgetting trauma is supported by the psychology literature, which suggests that individuals have a tendency to forget or repress past trauma [22] allowed them 
to cope with it. sport can help resolve identity by bringing people closer together; to provide an ice-breaker to initiate the complex process of reconciliation between divided communities; as a neutral platform to sustain the reconciliation past the initial stages; as rehabilitation; and as a 'hook' to keep traumatised youth coming back based education, rehabilitation or reintegration projects. Furthermore, amateur leagues and clubs in conflict zones can form a social network providing emotional support and physical protection for its members. sport inspires and motivates individuals and promotes self-esteem, physical and mental health and fosters positive connection with others [23].

\subsection{Overlap 4}

A Means toward Transformation The final findings of this research suggest that exposure-based initiatives, which introduce participants to new ideas and experiences may result in stimulate conflict transformation activities involve enhancing cooperative relations, encouraging non-violent mechanisms to deal with differences, empowering local populations to work out future disagreements among themselves without outside intervention [24]. This flow of effects represents a transformation in participants. These effects line up well with sport and peacebuilding literature. This link between the findings of this research and the literature can be demonstrated through that Sport can positively change participant"s attitude towards other identity groups and foster relationships [25]. Lederach [15] believes that 'statist diplomacy and realpolitik have not demonstrated a capacity to control protracted social conflicts. much less transform them toward constructive, peaceful outcomes' therefore what is also required is a flexible, sustainable infrastructure, to which 'relationship building and reconciliation are the key'. Kidd [20] demonctrated that sport is vehicle for broad, sustainable social development, especially in the most disadvantaged communities in the world. Participatory sport may cotribute to resolution if its serves as a central part in a structure to which other parts are connected and social networks can be formed between opposite groups, and can taught resolving conflict even while conflict persists. Sport fulfil a reconstructive role by enconuraging social reintegration, serving as a catchy point atractive participants to peacbuilding workshops and relationship rehabilitation [21]. sport can encourages new forms of social morphology community social ties, consciousness of other ethnic onational groups, promots human rights and citizenship agendas in divided societies and more inclusive conceptions co-existence. The open dialogue encourages critical reflexivity when addressing both internal and external criticisms, strengthen political and cultural engagement. [26]. Sugden [5] and Gasser \&Levinsen [27] recognizes that participatory sport as an tool to build relationships between members of divided sociaties. Participatory sport programs that bring to gether members of antagonistic groups may be able to creat crosscutting links at the grassroots level, increasing the chance of joining the divided groups. This type of bridging social captital at the grassroots level may be one of the most important outcomes that can achieved by sport peace initiatives. Sport can provide opportunities for social contact across community boundaries, promote mutual understanding, engender in participants a desire for and commitment to peaseful and coexistence, and technical knowledge equity and inclusion, respect, trust, and responsibility [5].

\section{Conclusion}

In the case of Iraq, differences among groups have been exploited by actors to further their own political or economic agendas, causing conflicts at different times between different groups. Conflict resolution interventions need to go beyond the conflict built by conflict promoters by exacerbating sectarian differences and focus instead on the social, political and economic instabilities at the root of the conflict. Any intervention aimed at conflict transformation, however, will have to address the newly developed perceptions of ethnic and religious differences. In order for sport to contribute to rapprochement, dialogue and reconciliation among peoples, it must be set going in this direction by an independent, transparent structure free of any political agenda, which cannot be suspected of serving particular interests of any kind. This is the price that has to be paid if we are to fully optimize the federating capacity of sport, to develop a structure intended to serve as a platform to federate ideas and drive initiatives [16]. Scholars and SDP advocates have both concluded that, when properly managed and designed, sport can play a constructive peacemaking role in communities affected by conflict and division [28, 29, 6, 19]. Sport-based interventions have emerged as useful tools to support peace-building efforts in highly volatile contexts due to, for instance, the ability of sport to maintain open channels of communication in hostile environments [19], and its capacity to connect people and develop networks of cooperation [6]. These characteristics found in sport can potentially contribute to reframing social relations between communities and groups that have been disrupted due to conflict [30].

\section{Recommendations}

1. The first actions undertaken as part of this partnership will be: to define an emergency response plan for postconflict and post-disaster situations, using sport as a tool for social integration, mental resilience and overcoming trauma; to develop social entrepreneurship through sport.

2. Second, we should have platform for professional, Olympic, and local athletes that strengthens the valuable role of these sports stars in peace building and global development initiatives. these athletes are role models, and therefore provide an important source of inspiration for the youth they meet living in extremely disadvantaged circumstances. It was found that strategic initiatives help ensure that the message portrayed 
through these athletes is one congruent with the progressive development goals of Peace and Sport. They are capable of mobilizing large fan-bases and sport networks to assist in additional resource collection for field projects, as well as actively raising awareness amongst key decision makers. They also provide guidance in designing training programs and help train coaches in the field. The champions with the highest coverage are not the only role models in a position to exert influence and take action: all sportspeople are potentially excellent local ambassadors when it comes to conveying the ethics of sport. Irrespective of the scale and extent of their fame, champions have a privileged opportunity to transmit and disseminate the values of sport in their social environment. Bouzou [16] explained, "we must embrace the athletes and the important influence they have, because that is not going away. There must be a platform for these athletes to truly engage and advocate for peace and global development."

\section{Acknowledgements}

Special thanks go to the lawyer Adnan Faleh Fadel (my husband), I extend my sincere thanks and gratitude for all the assistance and facilities he provided to complete the research and enable us to reach these dangerous areas and deal with them.

\section{References}

[1] Amnesty International. (2014a). Absolute Impunity: Militia Rule in Iraq. London: Amnesty International. Retrieved from: http://www.amnesty.org.uk/sites/default/files/absolute_impuni ty_iraq_report.pdf

[2] PAX. (2015a). Iraq Alert I - Recapturing Ninewa and Mosul: the need for post-ISIS peacebuilding. PAX.

[3] Cordesman, A. H. (2015). Iraqi Stability and the "ISIS War". Center for Strategic \& International Studies. Retrieved from: http://csis.org/files/publication/150812 Iraq_Stability and th e_War_on_ISIS.pdf

[4] European Peacebuilding Liaison Office (EPLO). (2014). Armed violence and capacities for peace in Iraq: Actors, causes, impact and EU responses. EPLO. Retrieved from: http://www.eplo.org/assets/files/2.\%20Activities/Civil\%20Soc iety\%20Dialogue\%20Network/Geograp hic\%20Meetings/Iraq-2014/CSDN_Iraq__Background_paper.pdf

[5] Sugden, John (2008). "Anyone for football for peace? The challenges of using sport in the service of co-existence in Israel". Soccer \& Society, Vol. 9, iss. 3, pp. 405-415.

[6] SPORT FOR DEVELOPMENT AND PEACE INTERNATIONAL WORKING GROUP (SDP IWG) (2008). Harnessing the power of sport for development and peace, Toronto: Right to Play.

[7] SCHIRCH, LISA (2005). Ritual and Symbol in Peace
Building. Bloomfield, CT: Kumarian Press.

[8] Arvidson, Joshua, Kristine Kinniburgh, and Kristin Howard, et al. 2008. 18 Colliard, Claire. "A Psychosocial Programme of Recreational Centres in Bam (Iran)." Center for Humanitarian Psychology and Terre des Hommes. March 2005: 39.

[9] Tsuchiya S, Sport as an International Tool for Development and Peace-building (2009 University for Peace in Costa Ricahttp://www.monitor.upeace.org/archive.cfm?id_article=62 1 , Retrieved on $10 / 10 / 2012$.

[10] KamberidouI. (2011) 'Athletes United for Peace: Reconciliation through Sport' in Sport as a Mediator between Cultures by Lidor, R. Schneider, K. and Koenen K. (Eds) Israel, International Council of Sport Science and Physical Education.

[11] Hesse-Biber, S. N. \&Leavy, P. (2011). The Practice of Qualitative Research. Thousand Oaks, California: SAGE Publications.

[12] Rossman, G.B. and Rallis, S.F. (2012) Learning in the Field: An Introduction to Qualitative Research. 3rd Edition, Sage, Los Angeles.

[13] David Bohm, On Dialogue (New York, NY: Routledge, 1996); Mohammed Abu-Nimer, "The Miracles of Transformation Through Interfaith Dialogue," in Interfaith Dialogue and Peacebuilding, ed. David R. Smock (United States Institute of Peace, 2002), 15-32.

[14] Snodderly, Dan, ed. Peace terms: Glossary for terms for conflict management and peacebuilding. Washington, DC: United States Institute of Peace, 2011.

[15] Lederach. The little book of conflict transformation. Intercourse, PA: Good Books, 2003.

[16] Bouzou, J. (2010). La paix par le sport: quand le mythe devient realites. Paris, France: Armand Colin / IRIS.

[17] Koshland, Lynn, J. Wilson, and B. Wittaker. "Peace through dance/movement: Evaluating a violence prevention program." American Journal of Dance Therapy 26, no. 2 (2004).

[18] Kornblum, Rena. Disarming the playground. Oklahoma City, OK: Woods and Barnes Publishing, 2002.

[19] Swiss Agency For Development And Cooperation (2005). Sport for development and peace. Berne.

[20] Kidd, Bruce (2011). "Cautions, questions and opportunities in sport for development and peace". Third World Quarterly, Vol. 32, iss. 3, pp. 603-609.

[21] Lea-Howarth, Jonathan (2006). Sport and conflict: is football an appropriate tool to utilize in conflict resolution, reconciliation or reconstruction? Contemporary War and Peace Studies, MA Dissertation, University of Sussex.

[22] Payne, J., Lynn Nadel, Willoughby J. Britton, and W. Jake Jacobs. "The biopsychology of trauma and memory." In Memory and emotion, edited by Daniel Reisberg and Paula Hertel, 76-128. New York, NY: Oxford University Press, 2004.

[23] UNESCO (2009). "Sport for Development \& Peace Proceedings". Zanzibar regional ministerial roundtable United Republic of Tanzania, 8-10 September 2008. 
[24] United Nations High Commissioner For Refugees (Unhcr) In Iraq Framework For Conflict-Sensitive Programming. Iraq Operation Amman, December 2007.

[25] Keim, Marion (2003). Nation-building at playsSport as a tool for social integration in postapartheid South Africa. Aachen: Meyer \& Meyer Verlag.

[26] Vertovec, S. (2009). Transnationalism. London, UK: Routledge.

[27] Gasser, P.; Levinsen, A. (2004). "Breaking Post-War Ice: Open Fun Football Schools in Bosnia and Herzegovina". Sport in Society, Vol. 7, iss. 3, pp. 457-472.
[28] Giulianotti, R.; Armstrong, G. (2011). "Sport, the Military and Peacemaking: history and possibilities". Third World Quarterly, Vol. 32, iss. 3, pp. 379-394.

[29] Woodhouse, Tom (2010). "Peace keeping, peace culture and conflict resolution". International Peacekeeping. Vol. 17, iss. 4, pp. 486-498.

[30] Rubinstein, R. (2011). Representation and response: Culture and conflict transformation (Conflict and Culture: Fostering Peace through Cultural Initiatives Report). Tokyo, Japan: Joint Research Institute for International Peace and Culture (JRIPEC) - Aoyama Gakuin University - The Japan Foundation New York. 